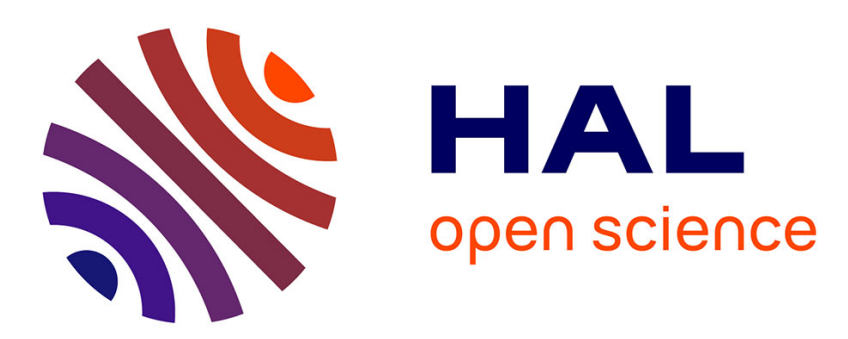

\title{
The ecological footprint as a follow-up tool for an administration: Application for the Vanoise National Park \\ Natacha Gondran
}

\section{To cite this version:}

Natacha Gondran. The ecological footprint as a follow-up tool for an administration: Application for the Vanoise National Park. Ecological Indicators, 2012, Volume 16, pp.Pages 157-166. 10.1016/j.ecolind.2011.09.036 . emse-00636523

HAL Id: emse-00636523

https://hal-emse.ccsd.cnrs.fr/emse-00636523

Submitted on 3 Nov 2011

HAL is a multi-disciplinary open access archive for the deposit and dissemination of scientific research documents, whether they are published or not. The documents may come from teaching and research institutions in France or abroad, or from public or private research centers.
L'archive ouverte pluridisciplinaire HAL, est destinée au dépôt et à la diffusion de documents scientifiques de niveau recherche, publiés ou non, émanant des établissements d'enseignement et de recherche français ou étrangers, des laboratoires publics ou privés. 


\title{
The ecological footprint as a follow-up tool for an administration: Application for the Vanoise National Park
}

\author{
Natacha Gondran \\ ENS des Mines de Saint-Etienne \\ Institut Henri Fayol \\ 158 cours Fauriel \\ 42023 Saint Etienne cedex 2 - France \\ Natacha.Gondran@emse.fr
}

Keywords: Environmental Management, Ecological footprint, National park

\begin{abstract}
Ecological footprint calculation methodology is generally well defined on a national scale. It is also proposed by several authors as a corporate sustainability metric, yet for this scale, there is no consensus method. The aim of this paper is to identify the consequences of such methodological liberties within the ecological footprint estimation and its use as a decision aid tool on the scale of a public organization.

The method was developed and validated for the Vanoise National Park which undertook to reduce its ecological footprint by $10 \%$ between 2009 and 2007 .

The methodological liberties inherent to ecological footprint analysis on an organization scale generate methodological choices that may influence the results in terms of environmental impact hierarchy and priority of actions. Therefore, such analysis requires transparency in the methodological choices behind the calculation and the involvement of the end-users in these choices.
\end{abstract}

Keywords: Environmental Management, Ecological footprint, National park

\section{Introduction}

Ecological footprint is aimed at comparing the demand on ecological services to available supply on a world scale. Such a metric is needed to make policy makers and people at large understand the threat of an overshoot of natural resources and to facilitate the emergence of a consensus over the actions needed to address the ecological risks (Ewing et al., 2008). First proposed by William Rees (Rees, 1992) (1992) and Mathis Wackernagel (Wackernagel, 1994)(1994), ecological footprint is mostly calculated and interpreted for Nations and the calculation methodology is now well documented for this scale (Ewing et al., 2010)

Ecological footprint calculations are also experimented on the scale of sub-national populations ((Chambers et al., 2002), (Barrett et al., 2003)). For example, the "Resources and Energy Analysis Programme" (REAP) aims at helping British local governments and agencies understand the footprints of residents by providing data, maps and reports on carbon and ecological footprints for local authority areas. In France, some local authorities have calculated their ecological footprint but only on a one-shot basis. Often, these 
calculations were made as a means of communication and raising awareness for the general public (Boutaud, 2009).

Since Barret and Scott proposed it (Barrett and Scott, 2001), numerous experiments have been conducted to use the ecological footprint (EF) as a corporate sustainability metric. However, they are generally based on a one-shot analysis and EF is not used as a follow-up and decision support tool for environmental management.

One of the first applications of ecological footprint for organizations to be published was conducted by (Chambers, N. and Lewis, K., 2001). These authors proposed a 7-step methodology: data scoping, data collection, assembling the footprint table, calculating the ecological footprint, normalization, scenarios and global sustainability assessments, refining the footprint/sensitivity analysis, Environmental management systems/using the footprint. The data collection appears to be the "most intense and challenging task". Indeed, few companies collate comprehensive data in the required format. Therefore, numerous assumptions and proxies are necessary. L. Holland (2003) also brings up the necessity of a clearly developed management information system that records not only financial data but also consumptions of material and energy, transportation of goods and persons and waste disposal in physical units. Ecological footprint analysis (EFA) encourages businesses to develop an environmental information system to provide a monitoring process and measure improvements. "This is perhaps its greatest strength - to incorporate hard science and ethical intuition into the assessment of business activity" (Holland, 2003). Indeed, ecological footprint translates various physical units into a single "currency". This currency can be hectare-years (Chambers, N. and Lewis, K., 2001) (1 hectare-year corresponds to the use of one hectare during one year) or hectare ( $\mathrm{Li}$ et al., 2008). However, the most usual unit used is the global hectare (gha) ((Lewis et al., 2005), (Wiedmann, 2008)), (Klein-Banai and Theis, 2011). It is a hectare that has the world average productivity of biologically productive land and water in a given year.

This aggregation relies on conversion factors that are used to convert different heterogeneous data, expressed in various units, into a single footprint unit. There is no consensual database of conversion factors. For example, Best Foot Forward commercializes the EcoIndex ${ }^{\mathrm{TM}}$ Methodology, whose database is proprietary (Chambers, N. and Lewis, K., 2001). CENSA developed TBL2 UK (Wiedmann and Lenzen, 2006a) (CenSA, 2008). These methods are based on the "shared responsibility" principle and the need for capturing impacts across the entire upstream and downstream supply chain (Wiedmann and Lenzen, 2006b).

These ecological footprint accounting methods were applied to public organizations. For example, the EF of Waverley Borough Council was calculated for the financial year 2007/2008 (CenSA, 2008). This study distinguished the impacts that are produced directly by the organization ( $38 \%$ of the total ecological footprint) and the ones associated to the consumption of goods and services, including electricity. Seven different types of land type were taken into account: fossil fuel energy footprint is due to the burning of fossil fuels and represents $84 \%$ of this footprint; nuclear energy footprint; crop land; pasture footprint; built-up land; sea footprint and forest footprint. The uncertainty of the results, expressed in gha, was estimated at $+/-13 \%$ (CenSA, 2008). The method used for this study, TBL2 UK, is based on an environmentally extended input-output-based LCA method and uses the 
financial accounts of the organization under study to provide both carbon and ecological footprint accounting (Wiedmann and Lenzen, 2006b). Input-output analysis is a top-down economic technique which is based on monetary transaction data between various industrial sectors. Thus, the conversion factors are obtained thanks to English macroeconomic data from the ONS National (economic) Accounts, ONS Environmental Accounts and GFN National Footprint Accounts (NFA).

This macroeconomic-based approach is not the one that was adopted by the French national agency for environment and energy efficiency (ADEME). Indeed, to estimate the carbon footprint of French companies, the ADEME developed its "Bilan Carbone ${ }^{\mathrm{TM}}$ ", aimed at calculating greenhouse gas emissions using consumption data and assessing the direct or indirect emissions produced by an activity (ADEME (Agence de l'Environnement et de la Maîtrise de l'Energie) - Mission Interministérielle de l'Effet de Serre, 2007), 2007) from physical and monetary data relating to the organization under study. This method is compatible with standard ISO 14064, the GHG Protocol initiative and the terms of the "permit" Directive No. 2003/87/CE relating to the CO2 quota trading system. Contrary to the carbon uptake footprint of the National Footprint Account, which only considers $\mathrm{CO}_{2}$ emissions, the "Bilan Carbone ${ }^{\mathrm{TM}}$ " takes the 6 main greenhouse gases covered by the Kyoto protocol and aggregates them via their 100 year global warming potential. Thus, it defines GHG emission factors which are based on LCA for the most frequent consumption products and services.

To come back to the main equation of ecological footprint:

$\mathrm{EF}_{\mathrm{c}}=\mathrm{EF}_{\mathrm{p}}+\mathrm{EF}_{\mathrm{I}}-\mathrm{EF}_{\mathrm{E}}$ (Ewing et al., 2008) where $E F_{p}$ is the Ecological Footprint of production, and $E F_{I}$ and $E F_{E}$ are the Footprints embodied in imported and exported commodity flows, respectively.

For a public organization like a National Park whose main mission is to provide services, $\mathrm{EF}_{\mathrm{p}}$ and $\mathrm{EF}_{\mathrm{E}}$ can be considered equal to 0 . Thus, the ecological footprint is equal to the sum of the ecological footprints of all the products that it bought during a given year. "The usefulness of $\mathrm{EF}$ as a stand-alone indicator for environmental impact is limited for product life cycles with relatively high mineral consumption and process-specific metal and dust emissions"(Huijbregts et al., 2008). However, EF is valuable for biological products. For example, the conventional production of wines was found to have a Footprint value almost double that of organic production, mainly due to the agricultural and packing phases (Niccolucci et al., 2008). It would appear to be interesting to consider not only a one-year field operation but also the whole lifetime of the system under study (Cerutti et al., 2010).

There are several methods of calculation of ecological footprint at the various possible scales of study. To ensure that Footprint assessments are produced consistently and to suggest community-proposed best practices, Ecological Footprint Standards 2009 (Global Footprint Network (GFN), 2009) were defined for sub-national population, product, and organization Footprint analysis and communication. However, these standards are not very directive as to the calculation methodology and the conversion factors. The aim of this paper is to identify the consequences of such methodological liberties within the ecological footprint estimation and its use as a decision aid tool for environmental management. What 
are the different possible methodological choices when estimating the ecological footprint of a public institution? Do these choices have an influence on the various options for action and the use of EF as a follow-up tool?

For a one-shot-analysis, public or private institutions may rely on commercial software that does not encourage them to question the hypothesis and conversion factors on which the tool is based. However, our assumption is that in the context of a decision-making support and follow-up tool, the understanding of these choices is essential. If the end-user cannot verify and control conversion factors, it may not trust commercial software and use it as a decision support and follow-up tool.

This study estimates the ecological footprint of the administration of the Vanoise National Park (VNP), in the Alps, France. This public institution is in charge of preserving the Vanoise Massif (Northern French Alps), obtaining knowledge of its natural and cultural heritage and making the public aware of the need to protect it. Thanks to its director's willingness, this public institution is involved in the environmental management of its activities and facilities. In its 2007-2009 Contract of objectives with the French Government, the VNP undertook to reduce its ecological footprint by $10 \%$ between 2009 and 2007 (Parc National de la Vanoise, 2007). Therefore, it needed an EF monitoring tool to identify actions in order to reach this ambitious objective and to verify its achievement. With the aim of using it as a follow-up tool, the VNP needed a calculator that it could easily make its own: easy to handle and understand, with open and transparent assumptions and corresponding to the French production patterns in terms of agricultural and forest yields and greenhouse gas emission factors and in particular consistent with the "Bilan Carbone" method (ADEME (Agence de l'Environnement et de la Maîtrise de l'Energie) Mission Interministérielle de l'Effet de Serre, 2007). The methodological liberties of ecological footprint calculation made it possible to draw up such a custom-made tool.

In this context, a partnership was set up with the Ecole Nationale Supérieure des Mines de Saint-Etienne and Aurélien Boutaud Conseil to carry out the three-year (2007 to 2009) follow-up of the ecological footprint of the Vanoise National Park. A steering committee, regularly bringing together the main stakeholders of the Vanoise National Park, discussed and validated the methodological choices of the EF analysis tool.

\section{Methods}

The Ecological Footprint aims at evaluating the human appropriation of ecosystem products and services in terms of the amount of bioproductive land and sea area needed to supply these services. The Ecological Footprint accounts cover six land use types: cropland, grazing land, fishing ground, forest land, built-up land and carbon uptake land (Ewing et al., 2010). For each component, the ecological footprint is obtained through the consumption of a harvested product (or amount of $\mathrm{CO}_{2}$ emission) divided by the yield for these ecological services. This value is then converted into "global hectares" thanks to yield and equivalence factors (Ewing and al., 2008b). 
These principles were considered to estimate the ecological footprint of the Park. The calculations were based on a component-based method that consists in inventorying every product and service consumed by the organization for the year under study and then applying various conversion factors for each type of land, corresponding to a certain unit of product or service ((Barrett et al., 2003), (Chambers, N. and Lewis, K., 2001)). To take into account the national production patterns, these conversion factors were calculated for the French situation (agricultural yields and emission factors, for instance) and for the year 2007 that is the reference year of the environmental management system of the Vanoise National park.

As the aim was to obtain a follow-up tool that the end-user could easily make its own and modify and that could be easily adapted to other national or regional parks, the EF tool was developed with commonly used computer applications such as MS Excel files that are linked together by Visual Basic for Application macros.

A five-step approach was followed to estimate the ecological footprint of the Park.

\subsection{Definition of the scope of the activity}

The first step was to define the scope of the activity under study (GFN, 2009). The activities for which the institution was a direct decision-maker were taken into account. In order to achieve its missions, the National Park is simultaneously:

- An owner of office buildings and park rangers' dwellings that use built-up areas, energy and water

- An employer of staff which travel from home to work and for their professional missions and get reimbursed for some meals during business trips

- A purchaser of goods and services

- A producer of waste that can be incinerated with or without energy recovery brought to landfills or recycled depending on the various places were the offices are located.

For all these activities, all the input and output fluxes were taken into account wherever the ecological footprint was generated.

75 items of consumptions which are listed in the first column of table 1, were taken into account. To facilitate the interpretation of the results, these items were grouped into categories that were inspired from (Chambers, N. and Lewis, K., 2001) and consistent with the actual information system of the Park. The buildings category rounds up built-up land, energy and water consumptions. Mobility includes home-to-work employee travel, business trips and freight. Food estimates the food products that were consumed by the employees during their business trips when they received meal expenses, and the lunches the Park organizes for special events. Manufactured goods account for the depreciation of durable goods (vehicles, computers, furniture, etc.), the manufacture of the consumer goods (office paper and furniture, for example) and the production of communication material as well as the waste generated by the staff of the Park. 
Initially, it was planned to account for all the operations for which the Park has operational control (Russell et al., 2010). In particular, it was intended to include the ecological footprint of the mountain refuges that are owned by the Park but managed by private refuge caretakers. However, the information on the relative energy consumption and the food served to the tourists was difficult to obtain and the Park could hardly impose ecological requirements on the food served preferring to promote a voluntary-based approach in favor of organic food consumption. This ecological footprint of the refuges is significant (about $25 \%$ of the total ecological footprint of the Vanoise National Park), however, it could not be monitored accurately.

Thus, a control/operational hybrid approach was preferred: the organization accounts for 100 percent of the ecological footprint from operations for which it has direct control (Russell et al., 2010) and for the energy used by Park-owned but employee-operated dwellings. The ecological footprint of the VNP-owned refuges was only estimated and presented separately from the Park ecological footprint.

\subsection{Identification and collection of consumption data}

The second step was to identify and collect the inventory and consumption data of the organization for years 2007, 2008 and 2009. Data had to be collected for 30 different consumption sites (headquarters, local offices, mountain refuges and huts, warden houses). This was a long and fastidious phase as the data required was rarely immediately available and likely to come from several information sources. The main sources of information were the financial accounts and the analysis of the numerous bills to obtain physical values ( $\mathrm{kWh}, \mathrm{km}$, litres, tons, etc.) that were preferred over monetary data when available, on-site data, employee survey and building energy audits.

In the case of a follow-up tool, it was important to record information sources to facilitate subsequent data collection. When collecting the information during the second and third years of study, some information collected the first year appeared to be incomplete or false. Therefore, unlike a one-shot study, this phase was consolidated thanks to the monitoring over several years. Furthermore, analyzing the evolution of the main ecological footprint components appeared to be a good management practice in order to identify evolution trends.

\subsection{Calculation of the footprint}

One of the main interests of EF is "to provide a partial solution to the sustainability aggregation problem by expressing environmental impacts in a single measurement unit" (Mamouni Limnios et al., 2009). Therefore, the third step consisted in organizing the information and calculating the conversion factors into global hectares.

The first challenge when organizing the information was to develop a tool that was both simple and complete. In particular, it was necessary to keep a record of the various 
consumptions of several categories of consumption (physical characteristics of buildings and the related water, electricity and other energy consumptions, transportation, freight, inventory of equipment depreciation, consumption of consumables, services and food) for several sites. Indeed, in order to foster the use of the footprint follow-up calculator, it was designed with several uses in mind: complete calculation of ecological footprint but also recording of the yearly consumptions of the various sites as an environmental management tool. The challenge of the EF calculation method was to be simple enough in order to be understood and appropriated by non-"ecological footprint experts".

In the literature, conversion factors are often picked up from previous studies (generally (Chambers, N. and Lewis, K., 2001) or (Barrett et al., 2003)). They are generally calculated or chosen by experts and not supposed to be discussed by the end-users of the EF calculator. However, some arbitrary choices are unavoidable in this step. Therefore, in order to weight the various items with coefficient both as similar as possible to the ones used by the National Footprint account so as to be coherent with EF national calculations and standards, and easily understood by the end-users of the tools, conversion factors were calculated with data issued from official statistical databases and then explained and discussed to the steering committee involving the main stakeholders of the Vanoise National Park.

For forest, cropland, fishing ground, grazing land, and built-up footprint, the classic equations of $\mathrm{EF}$ were used. For example, for cropland:

$E F_{\text {cropland }}=C_{i} * P_{i} * E F_{f} / Y_{c}$

$C_{i}$ : consumption of the item i (in tons/year)

$P_{i}$ : industrial productivity for the harvested product that is necessary for item $\mathrm{i}$

$Y_{c}$ : Yield per hectare for the type of crop that is necessary for item $\mathrm{i}$ (tons/ha)

$E F_{c}$ : equivalence factor for cropland (2.64 gha/ha according to (Ewing and al., 2008))

The same equation was used for fishing ground and grazing land respectively. To be consistent with NFA, the FAOSTAT database was used to identify crop yields of primary products for year 2007. This official database provides statistically reliable yields of primary products. However, various sources (professional federations, for example) were used to estimate industrial productivities between primary and secondary products. These yields are less reliable and vary according to various studies. As the Vanoise National Park gives priority to local products, the steering committee wanted the tool to take into account the ecological advantages of a local food supply. Therefore, the French yields, higher than the world yields, were taken into account for the food products that can grow in France. For the other products (bananas, for example), world yields were considered. The same approach was used for forest land. The yields that were taken into account aimed at representing the real yields that can be recorded for the different types of products consumed. Sources of data were AGRESTE (2010), UNECE Timber Committee and the FAO European Forestry Commission (2010). If the world yield of forest products had been considered, the consumption of wood logs for heating buildings would have represented more than $35 \%$ of the Park ecological footprint. In the Vanoise mountain context, wood log heating contributes in a positive manner to the forest management and is 
considered as a renewable energy. Giving such ecological weight to this practice was considered by the steering committee as counter-productive from an environmental management point of view. Local yields were therefore chosen.

Table 2 groups the yield and equivalence factors.

\section{Proposed place for Table 2}

\section{- Carbon uptake land}

The main originality of the method presented in this paper is the calculation of the carbon uptake land based on the 6 GES greenhouse gases considered by the Kyoto protocol (CO2, $\mathrm{CH} 4, \mathrm{~N} 2 \mathrm{O}, \mathrm{HFCs}$, PFCs and SF6) as opposed to the national footprint accounts that only consider $\mathrm{CO}_{2}$ emissions. French businesses, local authorities and public institutions are indeed encouraged to measure their carbon footprint with the "Bilan Carbone" method. A private or public organization will rarely analyze both its carbon and an Ecological footprint if the two methods are not consistent. Hence, the carbon uptake land of this study was based on the "Bilan Carbone » method (ADEME (Agence de l'Environnement et de la Maîtrise de l'Energie) - Mission Interministérielle de l'Effet de Serre, 2007), 2007). The 100 -year global warming potentials (GWP), the most commonly suggested method, was used to include CH4, N2O, HFCs, PFCs and SF6 in ecological footprint analysis ((Lenzen and Murray, 2001);(Barrett et al., 2003)). The GWP reflect the radiative forcing and atmospheric lifetime of each gas (IPCC 2001) and convert each gas into its carbon dioxide equivalent based on its ability to absorb and re-release radiation in the atmosphere over its projected atmospheric lifetime. (Kitzes et al., 2009).

The following equation was used:

$E F_{\text {carbon }}=C I^{*} F i^{*} 0,001 *\left(1-S_{\text {oceans }}\right) * E F_{c} / C S F$

where

$C_{i}$ : consumption of the item i (in tons/year)

$F i$ : greenhouse gas emission factor $\left(\mathrm{GWP}_{100}\right)$ for item i $(\mathrm{kg} \mathrm{Ceq} /$ ton of item i)

$S_{\text {oceans: }}$ percentage of anthropogenic emissions sequestered by oceans in a given year: $26 \%$ according to (Ewing and al., 2008)

$E F_{c}$ : equivalence factor for forest (1.33 gha/ha according to (Ewing and al., 2008))

$Y_{c}$ : annual rate of carbon uptake per hectare of world average forest land $(0.97$

tCeq/ha/year deduced from (Ewing and al., 2008)).

When available, the greenhouse gas emission factors were obtained from the Bilan Carbone $^{\circledR}$ method (ADEME, 2007). When there were not available, they were obtained from the Ecoinvent database (CML 2001 methodology) (Swiss centre for Life cycle inventories, 2010) or with LCA studies that were found in academic literature. 
Prior to 2008, the ecological footprint method treated nuclear power in the same manner as coal power. Since 2008, the Global Footprint Network no longer includes nuclear energy in NFA. As $78 \%$ of the French electricity is generated with nuclear power, the steering committee considered that this component could not be neglected considering the French electricity mix. Indeed, as ecological footprint was used as an aggregation tool to prioritize the various environmental aspects of the VNP, these risks and environmental impacts associated with nuclear technology could not be neglected. Using the low greenhouse gas emission factor of the French mix $\left(23 \mathrm{gC}_{\mathrm{eq}} / \mathrm{kWh}\right)$ would give very little importance to the impacts associated with electricity consumptions. Given that the European electricity network is increasingly interconnected, the steering committee chose to consider the European electricity mix $\left(96 \mathrm{gC}_{\mathrm{eq}} / \mathrm{kWh}\right)$ instead of the French one. This corresponds to $9.7 * 10^{-5}$ gha of carbon uptake land $/ \mathrm{GWh} / \mathrm{yr}$ and $4.7 * 10^{-7}$ gha of built-up area/GWh/yr. However, one of the Vanoise villages, Bonneval, is exclusively supplied with hydroelectricity. For the Bonneval buildings, the hydroelectricity mix was taken into account $\left(3.96^{*} 10^{-6}\right.$ gha of built-up area/GWh/yr).

Carbon footprint is correlated to the annual rate of carbon uptake. To be consistent with the GFN calculation, the same rate of carbon uptake as Hails (2008) was retained: $3.56 \mathrm{tCO}_{2 \mathrm{eq}} / \mathrm{ha} / \mathrm{yr}$. From a physical point of view, this data is rather uncertain and subject to changes with the varying carbon uptake capacities of forests. On the other hand, although the real figure is uncertain, the order of magnitude is confirmed by other studies. For example, the range of carbon uptake for Galician forest was estimated between 3.81 to $4.58 \mathrm{t} \mathrm{CO} 2 / \mathrm{ha} / \mathrm{yr}$ (Herva et al., 2010). This range is slightly higher than the global value used in the Living Planet Reports (3.67 t CO2/ha/yr in 2003 and 3.56 in 2005), but the Galician forests may have higher carbon uptake capacities than the world average and the greatest difference is less than $30 \%$.

Another factor that strongly influences carbon footprint is the percentage of anthropogenic emissions sequestered by oceans in a given year. It was fixed at $26 \%$ (Ewing and al., 2008). However, this percentage may significantly decrease over a long period of time because of the risk of saturation of the absorption capacities of the biosphere (Canadell, Pataki, on 2007). This would considerably increase the carbon footprint.

When using ecological footprint as a decision support tool, conversion factors that are based on natural resource productivity (for example, greenhouse gas emissions and crop production) are used to weight and aggregate different types of environmental impacts. The identification of conversion factors requires some inevitable choices to be made by the researcher defining the calculation method. To make the analysis as transparent as possible, these choices must be formalized clearly and should be discussed with experts in the various thematic fields concerned (forestry, agriculture, greenhouse gas, etc.). Table 1 groups the conversion factors chosen for this study.

The consumption data specific to the organization under study are then multiplied with the generic conversion factors to calculate the organization's ecological footprint. The results 
must then be verified by cross-checking and verification of the order of magnitude of the results of the various components.

\subsection{Analysis of results, scenario building and communication}

The fourth step is the synthesis and interpretation of the results in order to identify the main components of the ecological footprint. To interpret more easily the meaning and the evolution of the ecological footprint, EF results can be normalized according to the activity. However, as a public service provider, the activities of a National Park are multiple and hard to quantify: patrolling services to protect the natural area and its biodiversity, renovation of the built and natural heritage, monitoring of the state of the environment, work with local authorities, production of publications, etc. It could have been valuable to structure the $\mathrm{EF}$ calculation for each of these different final outputs. However, as there is no internal analytical accounting for the different resources used for each activity, only a global EF calculation was possible.

From an accounting perspective, the National Park's contribution to wealth could have been determined as the sum of staff cost and equipment depreciation. However, this monetary indicator may not represent the real contribution of a National Park very clearly. Indeed, the roles of public services are quite diverse and difficult to quantify. Besides, this accounting approach was not the one adopted by the Vanoise national Park (nor by the French administrations in general). Its most usual activity indicator is the number of Fulltime equivalents. A FTE of 1.0 is equivalent to a full-time worker for one year and accounts for seasonal workers proportionally to their work period. For example, a receptionist that works during the two summer months is accounted for as 0.17 FTE. Therefore, the results were presented in gha per FTE. This expression was well understood by the staff.

The aim of this ecological footprint analysis was not only to present an overview of the situation and its evolution but also to identify and quantify ways of action. Thus, the results and scenarios were presented and discussed with the Park management, its governing body and its staff (during its general assembly).

\section{Results}

The ecological footprint of the administration of the Vanoise National Park was estimated at $186 \mathrm{gha} / \mathrm{yr}(2.25 \mathrm{gha} / \mathrm{yr} / \mathrm{FTE})$ in $2007 \mathrm{and} 190 \mathrm{gha} / \mathrm{yr}(2.02 \mathrm{gha} / \mathrm{yr} / \mathrm{FTE})$ in 2009 . Figure 1 shows that although the absolute ecological footprint of the institution increased by $2 \%$ from 2007 to 2009, the ecological footprint per FTE decreased by 10\% between 2007 and 2009. Thus the Park did reach its EF reduction commitment.

\section{Proposed place for Figure 1}

The main source of improvement is due to the choice, since 2008, of recycled paper for the publications distributed by the Park. The reduction of ecological footprint is visible in Figure 1 (reduction of the forest land). However, this representation does not take into 
account the potential impacts of recycling paper on water effluents (Terasaki et al., 2008), nor the complete system boundary of the local waste management scheme (Merrild et al., 2008).

In 2007, 77\% of the Park's ecological footprint was made up of carbon footprint. However, forest land (18\%) and cropland (3\%) were significant. The main sources of ecological footprint are respectively buildings (in particular their energy consumption) (34\%), mobility (especially employee and committee travel) (26\%), manufactured goods (mainly communication products) (26\%), services (about 10\%) and food services (4\%).

From a decision support point of view, it was more relevant to identify the bigger contributors and to follow their evolution. Therefore, the various components were ranked according to their ecological footprint.

\section{Proposed place for Figure 2}

This figure underlines the main items that need to be improved. The ecological footprint hierarchy of items is different to that of the carbon footprint. For example, the consumption of wood heating energy represents a small carbon footprint. Because of the quantification of the forest land to grow the trees, it was the highest ecological footprint component. This conclusion was difficult to accept by the Park staff because it is considered as a renewable energy that should be promoted. Thanks to this representation, the evolution over the years of the various components was monitored in order to identify both the consequences of the environmental management practices and the unwanted evolutions.

\section{Proposed place for Figure 3}

Figure 3 shows, for example, the results of the thermal insulation building actions and investments into wood pellet boilers (reduction of the ecological footprints of wood log energy and fuel). On the other hand, it also shows that some attention should be drawn to the use of service providers and consumption of office and small consumables whose spendings are increasing. However, the ecological footprint of these three components are based on a ratio of ton of $\mathrm{CO}_{2}$ equivalent that are emitted per euro spent, based on the French average of carbon emissions of these activity sectors. Using this ratio is pragmatic as it is impossible to identify the real GHG emissions that are generated by each service provider. However, it is relatively inaccurate. Indeed, if the cost of a service or furniture increases, its ecological footprint will also increase even if the material and energy flows that are generated stay the same.

Ecological Footprint was also used as a prospective tool to estimate the ecological footprint reduction that could be generated by several possible environmental management actions. To define the scenarios, the "Negawatt approach" (Salomon et al., 2005), initially proposed for energy issues, was adapted to ecological footprint issues. The Negawatt approach first tackles the issue of 'how to consume better' before answering 'how to produce more'. 
It is based on three steps:

- "Sufficiency" (or consumption efficiency) consists of reducing wastefulness by rational individual behavior, organizational and societal choices: "consuming less"

- "Efficiency" means reducing as much as possible the losses of energy or matter for a certain use. It is often obtained by technological changes: "consuming better"

- "Renewable": "actions of sufficiency and efficiency can reduce our energy needs at their source. What still needs to be produced shall be provided by renewable energies, coming from amongst others our only true natural and everlasting source of energy: the sun" (Salomon et al., 2005)

For each type of action, two levels of ambition were considered: level 1 can be achieved rapidly and easily while level 2 is more ambitious and over the long term.

For example, electricity consumptions can be reduced by various complementary actions:

- Sufficiency: reduction of electricity demand through appropriate behavior and energy saving equipments can reduce the ecological footprint from 0.6 (level 1) to 1.3gha (level 2)

- Efficiency: refurbishment of the buildings where electricity is used as additional heating can reduce the ecological footprint from 0.8 (level 1) to 2.4 gha (level 2)

- Renewable energy: selecting electricity suppliers which use renewable energy sources can reduce the ecological footprint from 3.6 (level 1) to 10.2 gha (level 2).

\section{Proposed place for Figure 4}

Figure 4 represents the total EF improvements that can be obtained thanks to the various scenarios that were proposed.

\section{Discussion}

Table 3 shows that Ecological Footprint Analysis (EFA) methodology ranks building as the main contributor of EF while GHG emission analysis ranks mobility as the greatest contributor. Then, similarly to what was noticed by (Klein-Banai and Theis, 2011), the hierarchies of impacts evaluated by EFA methodology and GHG emission analysis are different as EFA gives more weight to the consumption of natural resources such as wood and food. Thus, EFA encompasses more environmental impacts than a GHG inventory. Therefore, it might be more relevant as an environmental management decision-aid tool.

\section{Proposed place for Table 3}

87 components had to be informed to fulfill a complete ecological footprint analysis. As each component is itself a combination of one to 30 raw data (bills, for example), the process of gathering information may be long and costly (about two persons-months for an administration with about 85 employees). Not all public organizations can afford to spend so many hours monitoring their environmental pressures. However, as only 22 components contributed to $90 \%$ of the 2007 ecological footprint, the process of updating the data could 
be shortened if only these components were updated. Nonetheless, $10 \%$ of the Ecological footprint would remain uncertain and this uncertainty margin exceeds the reduction commitment of 5 percent each year. Fuzzy logic could be used as a way of dealing with uncertainty in the input data and reducing the need of environmental data (González et al., 2002), (Beynon and Munday, 2008).

Ecological footprint was used as an internal metric to prioritize impacts and to quantify environmental abatement options, as proposed by (Baboulet and Lenzen, 2010). It aggregates various types of impacts into a common unit. The choice of conversion factors (forest and crop yields, annual rate of carbon uptake, greenhouse gas emission factors, for example) has a strong influence on the final hierarchy of results. Although these coefficients are based on scientific studies or official statistical databases, they must be questioned. They are in fact subject to variations. For example, forest yields may vary considerably according to the various forest products. For instance, timber productivity for paper products or heating firewood is higher than for wooden furniture. Climatic conditions may affect crop and forest yields. The different industrial processes that can be used to produce the same type of manufactured products may generate very different amounts of greenhouse gas emissions. The choice of these conversion factors may affect the final results substantially, and thus the hierarchy of ecological footprint components... and the actions to be considered in priority.

Therefore, when drawing up the ecological footprint calculator, some choices are unavoidable. The understanding of these assumptions by the organization's decisionmakers is indispensable. The bottom-up methodology that was used in this study makes it possible to clarify each methodological choice and to jointly define the conversion factor the most suited to each product or service used. It appears to be more flexible than a compound approach, where the same environmental factor is used for any monetary exchange between two given activity sectors, whatever the specificity of the product exchanged.

Another issue was the choice of crop yield factors. In actual fact, the Vanoise National Park promotes the use of organic farming in its territory and purchasing policy (for food, textiles, etc.). Therefore, it wanted to highlight the benefits of organic farming against intensive agriculture. However, organic farming generates a lower yield per unit of land and thus requires larger areas than intensively cultivated land to produce a similar quantity of products, so it has a larger crop and grazing EF (Mozner and Tabi, 2010). However, intensive agriculture uses more manufactured products (fertilizers, insecticides, herbicides, etc.) and generates more greenhouse gas emissions than organic farming. Thus, smaller greenhouse gas emission factors should be used to estimate the ecological footprint of organic products (Niccolucci et al., 2008), but larger cropland yield factors than for intensive agriculture. However, considering the negative impacts of intensive agriculture on soils (erosion, depletion of soil nutrients, etc.), it was not acceptable for a decisionmaker wishing to promote organic farming to introduce into its follow-up tools, crop yields that would favor, on the cropland footprint side, intensive farming rather than organic. Therefore, the same crop yields were used regardless of the origin of the products. 
However, it may be interesting to take into account "sustainable yields" to calculate the cropland footprint. The cropland footprint could be considered as the area required to sustainably cultivate the crops that are used by a given organization or population, whatever their real mode of production, thereby increasing the cropland footprint. This methodological choice could also be used for sub-national or national footprint accounts (NFA). Indeed, in the actual NFA, biocapacity and cropland ecological footprint are constructed as equal: no cropland overshoot can be observed whereas the over-exploitation of farmland is a well-known and worrying issue. If the crop biocapacity remains calculated with the actual yields whereas the crop footprint takes into account "sustainable yields", the crop footprint would appear larger than the biocapacity. This could clearly highlight the over-exploitation of farmland. This difference between the natural capacity of farmland (the so-called "sustainable yields") and artificial and unsustainable yields that are currently recorded could be explained by the use of industrial products to overharvest farmland. Such a methodological change within the national ecological footprint accounts would appear urgent in order to promote the use of ecological footprint as a decision aid tool. The current method does in fact put organic farming at a disadvantage. This issue was emphasized by the French Commissariat général au développement durable - Service de l'observation et des statistiques (CGDD-SOeS - general commissariat for sustainable development - Department for Observation and Statistics) during its expert examination of the Ecological Footprint where it tested a switch to organic farming, 'other things being equal' (Tregouet, 2010) and concluded that "The exercise revealed the limits, and even the dangers, of a purely mechanical approach". Indeed, with the current method, if a country switches broadly to organic farming, its carbon footprint may decrease, but its cropland footprint may, on the contrary, increase.

To aggregate greehouse gas emissions, the 100-years GWP (Global Warming Potential) is generally used by regulators and environmental databases like Ecoinvent (Swiss centre for Life cycle inventories, 2010). This GWP method can be interpreted as indicating the amount of additional carbon dioxide that would need to be sequestered to balance the equivalent of other greenhouse gas emissions. Therefore, it was the method that was chosen in this study. However, "the warming potential of a greenhouse gas is arguably unrelated to the biosphere's regenerative capacity for these materials. A global warming potential method will become more difficult to justify as these other gases begin to form a larger, non-marginal fraction of total warming potential”. (Kitzes et al., 2009) Besides, while $\mathrm{CO} 2$ can persist in the atmosphere for several centuries, methane disappears in a few decades. Therefore, its impact varies largely over time: over twenty years its warming power is seventy times that of $\mathrm{CO} 2$; over a hundred years, only twenty-four times. Methane's contribution to warming is therefore much greater in the short term than is expressed by the 100-year GWP (Dessus et al., 2008). In the context of our study, methane emissions are neglectable, so this is not an important issue. However, in the case of organizations that generate methane emissions (landfill, livestock farming, for example), this aggregation method should be used carefully as the hierachy of environmental impacts - and consequently the priority of actions to implement - obtained with a 100-year GWP may be very different from the one that would be get with a 20 -year GWP. 
601

Another difficulty with using ecological footprint as a follow-up tool is linked to the yearly actualization of conversion factors. Indeed, when rigorously calculating the ecological footprint of a new year, conversion factors should be updated to take into account the annual yields (of harvested products, for example) of the new year under study. However, if such a method is chosen, the variations of ecological footprint over the years can be explained by two factors: changes in the consumptions of the organization and/or changes to conversion factors. The latter are linked to variations of productivity of national or even world-wide productivity and are independent from the decisions of the organization under study. From a decision support point of view, this is not satisfactory: the organization wants to monitor only the changes it is responsible for. Therefore, it only wants to track changes that are linked to the evolution of its own consumptions. So, the "constant global hectare" Method was chosen (Kitzes et al., 2007) and the 2007 conversion factors were used for the three years under study.

\section{Conclusion}

Although the analysis of ecological footprint for a National Park raises several methodological and conceptual questions, this study shows that it has some obvious benefits as a decision support tool for environmental management. It contributed to making the employees and stakeholders more aware of the pressures that are generated on biological resources (for example, wood consumption for paper, heating, etc). It also raised awareness of the issues that were ignored because they were not directly visible to the endusers (for example, the end-user of a tee-shirt has no idea of the surface area required to grow the cotton of this tee-shirt). The component-based approach chosen for this study led to the implementation of an internal information system based on physical flow data $(\mathrm{kWh}$, tons of fuel, tons of wood, etc.) and flows that are not directly paid by the administration but that are generated by its activity or facilities (home-to-work travel, energy consumption of employees living in the organization's accommodation, for example). This has given the institution a greater overview of its impacts and has generated interesting discussions among the steering committee and the staff as to its responsibility as an employer, a service and goods purchaser, but also a housing service provider. Monitoring these data over three years underlined their evolution trends and enabled to inform decision-makers of the reductions or increases in these various consumptions. Thanks to this study, environmental actions could be identified as well as goals of improvement and the progress or distance towards these goals to be tracked.

Ecological Footprint aggregates various types of environmental pressures on the basis of conversion factors stemming from biophysical data. Multi-criteria analysis methods may also aggregate such pressures but their weighting is often obscure and based on the point of view of experts rather than biophysical data. Besides, contrary to monetary indicators that aim to internalize ecological externalities, ecological footprint does not rely on the 
hypothesis that natural resources could be substituted by human capital (money, culture, knowledge, facilities, etc.) (Boutaud and Gondran, 2009).

However, ecological footprint on the scale of an organization should be used with care. First of all, its analysis is time and cost-consuming for the collection of data and calculations. Besides, methodological liberties that are inherent to ecological footprint analysis generate methodological choices that may influence the results in terms of environmental impact hierarchy, and thus the priority of actions that arise from the study. Indeed, numerous conversion factors are hidden behind the simplicity of results with a single unit. Thus, some pressures that could have been emphasized with different conversion factor choices may be under-estimated. Therefore, the choice of conversion factors must be discussed and presented clearly to the end-user of the tool.

To conclude, although the ecological footprint of an organization can definitely be estimated and used as a decision support tool for environmental management, it does require efforts in order to make the end-users understand the methodological choices behind the calculation. Therefore, the simpler the method, the more satisfactory it is as a decision support tool for environmental management.

\section{Acknowledgements}

Special thanks to the Vanoise National Park (and especially to P. Traub, its Director, J.L Gosselin and L. Ougier) and to A. Boutaud.

Several students of the Ecole Nationale Supérieure des Mines de Saint-Etienne contributed to this study (C. Rigal, A. Cikankowitz, L. Autixier, H. Tiersonnier, E. Plancher, D. Barbachou and F. Alvares Leite). Deirdre McArdle-Epinat edited the English language of this paper. I wish to thank them all.

I would like to thank the two unknown reviewers for their constructive comments.

\section{References}

ADEME (Agence de l'Environnement et de la Maîtrise de l'Energie) - Mission Interministérielle de l'Effet de Serre, 2007), 2007. Guide des facteurs d'émissions, Version 5.0, Calcul des facteurs d'émissions et sources bibliographiques utilisées. , $240 \mathrm{p}$.

Baboulet, O., Lenzen, M., 2010. Evaluating the environmental performance of a university. J. Clean. Prod. 18, 1134-1141.

Barrett, J., Scott, A., 2001. The Ecological Footprint: A Metric for Corporate Sustainability. Corporate Environmental Strategy 8, 316-325.

Barrett, J., Vallack, H., Jones, A., et al., 2003. A Material Flow Analysis and Ecological Footprint of York., 1-9.

Beynon, M.J., Munday, M., 2008. Considering the effects of imprecision and uncertainty in ecological footprint estimation: An approach in a fuzzy environment. Ecol. Econ. 67, 373-383.

Boutaud, A., 2009. Les agendas 21 locaux - Bilan et perspectives en Europe et en France. 
Boutaud, A., Gondran, N., 2009. L'Empreinte Écologique, Collection Repères ed. La Découverte, Paris.

Canadell, J.G., Pataki, D., Pitelka, L., 2007. Terrestrial Ecosystems in a Changing World, The IGBP Series ed. Springer-Verlag, Berlin Heidelberg.

CenSA, 2008. An Ecological Footprint Analysis of Waverley Borough Council. 08-03, 119.

Cerutti, A.K., Bagliani, M., Beccaro, G.L., Bounous, G., 2010. Application of Ecological Footprint Analysis on nectarine production: methodological issues and results from a case study in Italy. J. Clean. Prod. 18, 771-776.

Chambers, N. and Lewis, K., 2001. Ecological Footprint Analysis: Towards a Sustainability Indicator for Business. 65.

Chambers, N., Heap, R., Jenkin, N., Lewis, K., Simmons, C., Tamai, B., Vergoulas, G., Vernon, P., 2002. A Resource Flow and Ecological Footprint Analysis of Greater London.

Dessus, B., Laponche, B., Le Treut, H., 2008. Effet de serre : n’oublions pas le méthane ! . La Recherche $\mathrm{n}^{\circ} 417$.

Ewing, B., Goldfinger, S., Wackernagel, M., Stechbart, M., Rizk, S.M., Reed, A., Kitzes, J., 2008. The Ecological Footprint Atlas 2008.

Ewing, B., Moore, D., Goldfinger, S., Oursler, A., Reed, A., Wackernagel, M., 2010. The Ecological Footprint Atlas 2010.

Ewing, B., Reed, A., Rizk, S.M., Galli, A., Wackernagel, M., Kitzes, J., 2008. Calculation Methodology for the National Footprint Accounts, 2008 Edition.

Global Footprint Network (GFN), 2009. Ecological Footprint Standards 2009.

González, B., Adenso-Díaz, B., González-Torre, P.L., 2002. A fuzzy logic approach for the impact assessment in LCA. Resour. Conserv. Recycling 37, 61-79.

HAILS, C. (ed.), 2008. Living Planet Report 2008. WWF International, Gland, http://wwf.panda.org/about_our_earth/all_publications/living_planet_report/living_planet_ report_timeline/lpr_2008/

Herva, M., Hernando, R., Carrasco, E.F., Roca, E., 2010. Methodological advances in Ecological Footprinting, Footprint forum 2010.

Holland, L., 2003. Can the principle of the ecological footprint be applied to measure the environmental sustainability of business? Corporate Social Responsibility and Environmental Management 10, 224-232.

Huijbregts, M.A.J., Hellweg, S., Frischknecht, R., Hungerbühler, K., Hendriks, A.J., 2008. Ecological footprint accounting in the life cycle assessment of products. Ecol. Econ. 64, 798-807.

Kitzes, J., Galli, A., Wackernagel, M., Goldfinger, S., Bastianoni, S., 2007. A "Constant Global Hectare" Method for Representing Ecological Footprint Time Trends. International Ecological Footprint Conference .

Kitzes, J., Galli, A., Bagliani, M., Barrett, J., Dige, G., Ede, S., Erb, K., Giljum, S., Haberl, H., Hails, C., Jolia-Ferrier, L., Jungwirth, S., Lenzen, M., Lewis, K., Loh, J., Marchettini, N., Messinger, H., Milne, K., Moles, R., Monfreda, C., Moran, D., Nakano, K., Pyhälä, A., 
Rees, W., Simmons, C., Wackernagel, M., Wada, Y., Walsh, C., Wiedmann, T., 2009. A research agenda for improving national Ecological Footprint accounts. Ecol. Econ. 68, 1991-2007.

Klein-Banai, C., Theis, T.L., 2011. An urban university's ecological footprint and the effect of climate change. Ecol. Ind. 11, 857-860.

Lenzen, M., Murray, S.A., 2001. A modified ecological footprint method and its application to Australia. Ecol. Econ. 37, 229-255.

Lewis, K., Vergoulas, G., Jenkin, N., 2005. An Ecological Footprint Analysis of the Countryside Council for Wales.

Li, G.J., Wang, Q., Gu, X.W., Liu, J.X., Ding, Y., Liang, G.Y., 2008. Application of the componential method for ecological footprint calculation of a Chinese university campus. Ecol. Ind. 8, 75-78.

Mamouni Limnios, E.A., Ghadouani, A., Schilizzi, S.G.M., Mazzarol, T., 2009. Giving the consumer the choice: A methodology for Product Ecological Footprint calculation. Ecol. Econ. 68, 2525-2534.

Merrild, H., Damgaard, A., Christensen, T.H., 2008. Life cycle assessment of waste paper management: The importance of technology data and system boundaries in assessing recycling and incineration. Resour. Conserv. Recycling 52, 1391-1398.

Mózner, Z., Tabi, A., 2010. Comparing the environmental impacts of intensive and extensive agricultural practices. Footprint forum 2010, Colle di Val d'Elsa and Siena, June $7-12,2010$.

Niccolucci, V., Galli, A., Kitzes, J., Pulselli, R.M., Borsa, S., Marchettini, N., 2008. Ecological Footprint analysis applied to the production of two Italian wines. Agric. , Ecosyst. Environ. 128, 162-166.

Parc National de la Vanoise, 2007. Contrat d'objectifs Etat-Etablissement public du Parc National de la Vanoise 2007 - 2009.

Rees, W.E., 1992. Ecological Footprints and appropriated carrying capacity: what urban economics leaves out. Environment and Urbanization 4, 121-130.

Russell, S., Sotos, M., Bostock, V., Canes, M., Dzuray, E., Hardison, H., Jonassen, R., Kalloz, J., Poche, S., 2010. The Greenhouse Gas Protocol for the U.S. Public Sector: Interpreting the Corporate Standard for U.S. Public Sector Organizations .

Salomon, T., Couturier, C., Jedliczka, M., Letz, T., Lebot, B., 2005. A negawatt scenario for 2005-2050. ECEEE.

Swiss centre for Life cycle inventories, 2010. Ecoinvent database. v2.2.

Terasaki, M., Fukazawa, H., Tani, Y., Makino, M., 2008. Organic pollutants in paperrecycling process water discharge areas: First detection and emission in aquatic environment. Environmental Pollution 151, 53-59.

Tregouet B. (dir.), 2010. An expert examination of the Ecological Footprint. Observation et statistiques. $\mathrm{n}^{\circ} 16$, http://www.statistiques.developpementdurable.gouv.fr/fileadmin/documents/Produits_editoriaux/Publications/Etudes_et_docume nts/2010/An_expert_examination_of_the_Ecological_Footprint_03.pdf 
766 Wackernagel, M., 1994. Ecological Footprint and Appropriated Carrying Capacity: A Tool

767 for Planning Toward Sustainability.

768 Wiedmann, T., 2008. The Carbon Footprint and Ecological Footprint of the Scottish

769 Parliament. 08-01, 1-14.

770 Wiedmann, T., Lenzen, M., 2006a. Sharing Responsibility along Supply Chains - A New

771 Life-Cycle Approach and Software Tool for Triple-Bottom-Line Accounting. The

772 Corporate Responsibility Research Conference 2006.

773 Wiedmann, T., Lenzen, M., 2006b. Triple-Bottom-Line Accounting of Social, Economic 774 and Environmental Indicators - A New Life-Cycle Software Tool for UK Businesses.

775 Third Annual International Sustainable Development Conference "Sustainability -

776 Creating the Culture".

777 